\title{
Todo lo que vive, depende Resignificando la vulnerabilidad corporal humana y el trabajo de cuidados en tiempos pandémicos
}

d.i) https://doi.org/10.21814/anthropocenica.3291

\author{
Sílvia Lilian Ferro \\ Instituto Latino-americano de Economía, Sociedade e Política (ILAESP), Universidade Federal da \\ Integração Latino-americana (UNILA) \\ Brasil \\ lilian.ferro@unila.edu.br \\ ORCID: 0000-0003-2551-801X
}

\section{Resumen}

Se analiza en perspectiva histórico-ambiental la experiencia actual de la pandemia, como parte de un continuum en la historicidad de la vulnerabilidad, humana y no humana, inherente a la corporalidad. Se cuestiona sobre la posible finalización de una larga etapa posmoderna construida sobre binarios jerárquicos - como racionalidad y animalidad, masculinidad y femineidad, sociedad y naturaleza propiciada por impactos culturales pospandemia. Por último, problematiza la contradicción que subyace a ser especie dominante planetariamente y simultáneamente la más vulnerable físicamente, por ello la más dependiente de cuidados provistos por otros. La metodología se basa en el diálogo epistemológico interdisciplinar entre Humanidades enfocadas en el cuerpo como objeto de conocimiento, con conceptos de la Historia Ambiental y Global, así como de Estudios Feministas. Se concluye que la tentativa de ocultamiento de la dimensión animal y la dependencia que genera su vulnerabilidad intrínseca, se traslada a la mirada pública sobre trabajos de cuidados familiares, atribuidos culturalmente a las mujeres. Las cuarentenas en gran parte del mundo, acentúan la contradicción entre seguir minusvalorando la importancia biológica y social del trabajo de cuidados familiares y sobrevalorando el cuidado sanitario provisto por instituciones de salud, apenas punta del iceberg del cuidado implicado para sostener la vida humana.

Palabras clave

Cuidados; Pandemia; Historia Ambiental y Global; Estudios Feministas

\begin{abstract}
The current experience of the pandemic is analyzed from a historical-environmental perspective, as part of a continuum in the historicity of human and non-human vulnerability inherent to corporality. The possible end of a long postmodern stage built on hierarchical binaries - such as rationality and animality, masculinity and femininity, society and nature - caused by post-pandemic cultural impacts, is questioned. Finally, it problematizes the contradiction that underlies being the dominant species on a planetary basis and simultaneously the most physically vulnerable, hence the most dependent on care provided by others. The methodology is based on the interdisciplinary epistemological dialogue between Humanities focused on the body as an object of knowledge, with concepts from Environmental and Global History, as well as Feminist Studies. It is concluded that the attempt to conceal the animal dimension and the dependency that its intrinsic vulnerability generates, moves to the public eye on family care work, culturally attributed to women. Quarantines in much of the world accentuate the contradiction between continuing to underestimate the biological and social importance of family care work and overvaluing the health care provided by health institutions, just the tip of the iceberg of the care involved in sustaining human life.
\end{abstract}

Keywords

Care; Pandemic; Environmental and Global History; Feminist Studies. 
A experiência atual da pandemia é analisada a partir de uma perspetiva histórico-ambiental, como parte de um continuum na historicidade da vulnerabilidade, humana e não humana, inerente à corporeidade. Questiona-se acerca da possível conclusão de um longo estágio pós-moderno construído por binários hierárquicos - como racionalidade e animalidade, masculinidade e feminilidade, sociedade e natureza causado por impactos culturais pós-pandêmicos. Por fim, problematiza-se a contradição que está por trás de ser a espécie dominante numa base planetária e, simultaneamente, a mais vulnerável fisicamente e, portanto, a mais dependente do cuidado de terceiros. A metodologia baseia-se no diálogo epistemológico interdisciplinar entre as Humanidades com foco no corpo como objeto de conhecimento, com conceitos oriundos da História Ambiental e Global, bem como dos Estudos Feministas. Conclui-se que a tentativa de ocultar a dimensão animal e a dependência que a sua vulnerabilidade intrínseca gera, é transferida aos olhos do público para o trabalho de cuidado à família, culturalmente atribuído às mulheres. Quarentenas em grande parte do mundo acentuam a contradição entre continuar a subestimar a importância biológica e social do trabalho de cuidado familiar e sobrevalorizar os cuidados de saúde prestados por instituições de saúde, apenas a ponta do iceberg de cuidados envolvidos na manutenção da vida humana.

Palavras-chave

Cuidados; Pandemia; História Ambiental e Global; Estudos Feministas

\section{Introducción}

Las pandemias no son algo novedoso en la historia de nuestra especie. Por el contrario, son de los procesos históricos mejor documentados ${ }^{1}$. De acuerdo con Alexandre Sampaio Moura y Regina Lunardi Rocha, investigadores del Núcleo de Educação em Saúde Coletiva de la Universidade Federal de Minas Gerais,

Grandes epidemias moldearon la historia de la humanidad, destacándose entre ellas la peste negra, los brotes de cólera, la tuberculosis (también denominada peste blanca) y la fiebre amarilla. (...) Diferentes agentes, como protozoarios, virus y bacterias, son los responsables por las endemias y epidemias mas relevantes en todo el mundo (Moura \& Rocha, 2012, p. 8).

La enfermedad es una característica intrínseca de la corporeidad en cuanto organismo ${ }^{2}$ biológico y el contagio puede ser una consecuencia tanto de la convivialidad, intensa en el caso humano, como de las interacciones entre el ambiente interno de cada cuerpo con el ambiente externo según las diferentes concepciones en la historia de la Epidemiología. En cuanto al planteo "contagionista" la incidencia de las epidemias constantes en la Historia humana podría atribuirse el inicio de su existencia al cambio dramático de las condiciones de vida que siguió a la primera Revolución Agrícola entre 12.000 a 10.000 años antes de nuestra era, que propició el sedentarismo resultante de la domesticación de las plantas y animales para su consumo:

\footnotetext{
1 Al respecto Czeresnia (1997) informa que "El relato de Tucídides, en 430 a.C, sobre la epidemia que sucedió luego de la invasión de la ciudad de Atenas durante la guerra del Peloponeso, es importante documento histórico" (p.16).

2 Trayendo al análisis la visión cartesiana, también Czeresnia (1997) informa que: "Concebido de esa manera, el concepto de organismo quedó fuertemente marcado por una visión dual de hombre [ser humano], que lo divide en cuerpo y alma." (p. 21).
} 
Los antiguos cazadores-recoletores también eran menos afectados por enfermedades infecciosas (...) la mayoría de las personas en las sociedades agrícolas e industriales vivían en asentamientos permanentes que eran populosos y poco higiénicos - una incubadora ideal para las enfermedades. Los antiguos cazadores-recoletores recorrían la tierra en pequeños bandos lo que no alimentaba epidemias. (Harari, 2018, pp. 80-81)

En esa línea, el autor también coloca en consideración el impacto en las condiciones de salud de los Homo Sapiens, del establecimiento de la agricultura debido a la pérdida de diversidad de la dieta, dependiendo a partir de ese momento de un repertorio alimentario gradualmente menor; incrementado el consumo de granos y animales en forma permanente.

Así como otros especialistas del campo, Harari menciona el hecho que, en los 200.000 años aproximadamente de evidencia de presencia de la especie en el planeta, apenas hace 10.000 años que se experimenta el sedentarismo en forma continua, en la mayoría de los grupos humanos. Es decir, más del $90 \%$ del tiempo de la existencia humana estuvo caracterizado por la caza-recolección (Harari, 2018). Esto habría incidido, para el autor, en una progresiva pérdida de conexión mental con el cuerpo ya que esta, en sociedades sedentarizadas, viviendo en grupos estables podría ser menos importante respecto al extenso periodo anterior: "Los cazadores-recoletores dominaron no solo el mundo de [otros] animales, plantas y objetos alrededor, como también el mundo interno de su cuerpo y sensaciones" (Harari, 2018, p. 77).

En la literatura antigua conservada hasta nuestro día es posible identificar en el periodo de la Antigüedad Clásica mediterránea la etapa de mayor producción de ideas fundamentando la desconexión entre la dimensión cultural humana - la que posibilita la convivencia y el conocimiento - de la dimensión animal, espacio de la naturaleza radicada en su propio cuerpo. La Filosofía grecoromana antigua dejó abundante testimonio sobre la deseable separación y jerarquización entre la dimensión corporal y la dimensión racional y/o espiritual humana. Por ejemplo, en el pensamiento de Platón el cuerpo mortal es la cárcel del alma inmortal, la obstaculiza al crearle deseos, temores, pasiones que la atormentan impidiéndole alcanzar niveles elevados de virtud y de libertad plena para buscar la verdad. Le crearía también, ambiciones provenientes del mundo sensible, que provocan violencia y destrucción. Por ello, el cuerpo se vuelve una pesada carga para el alma y ésta tiene que esforzarse en purificarse a lo largo de su existencia aprisionada en la carne. Ya Aristóteles, le retira al cuerpo el rol platónico de villano, aunque lo concibe subalternizado, instrumento de la realización de la volición del alma: "Pensando el cuerpo vivo como animado y organizado, y en él enfatizando la subordinaçión de los órganos en relaçión al 
alma, Aristóteles afirma que los órganos son instrumentos de los fines del alma." (Czeresnia, 1997, p. 21)

Esas ideas, aunque surgidas en contextos paganos, fueron asimiladas en las principales religiones monoteístas de origen también mediterráneo:

Históricamente, el símbolo mas potente del mundo profano es el cuerpo humano. El cuerpo es peligroso, y sus secreciones, en particular el semen y la sangre menstrual, deben ser contenidos con rituales y tabús con el fin de protegerse el orden social (Turner, 2008, p. 124).

Más adelante, para los ilustrados - a excepción de Rousseau - los deseos y ambiciones sensoriales que el cuerpo genera y alberga son inspiradores de las violencias que el Estado es llamado a contender y en la mirada de los contractualistas, para proteger la armonía social que permite la civilización de las costumbres y el progreso técnico. Por ejemplo, para Hobbes ([1651] 1980) el cuerpo - y sus deseos, así como de su derecho a la autopreservación - ámbito del estado de naturaleza del ser humano, es causante de violencia generalizada de unos contra otros y por tanto es necesaria la convivencia social y sus normas para disciplinar los impulsos naturales humanos que nos llevaria a vidas embrutecidas, violentas y cortas. Para Rousseau ([1755] 1999) sin embargo, es la vida social la que corrompe la bondadosa, inocente y empática condición humana inicial es decir en estado de naturaleza antes de la llegada del sedentarismo, la ciudad, la proximidad constante, el conflicto resultante y el estado para administrarlo. En suma, de la civilización.

\section{El cuerpo humano y sus indiscreciones}

Es en la Modernidad cuando advertimos el ápice de las ideas de subordinación del cuerpo a la mente racional desde donde se proyecta el ser humano racional y espiritualizado hacedor de cultura, ciencia y trascendencia. El ascenso de las ciencias experimentales desde el siglo XVII, aparece como el triunfo de la razón sobre la naturaleza, a la que se conquista y domina a partir de conocerla, igual que a las mujeres. En palabras de Immanuel Kant (citado en Roldán, 2013): “La mujer es entonces un animal doméstico” (p.194). Es decir, para el filósofo serían éstas seres que pertenecen a territorios intermedios entre la naturaleza donde reside lo no humano y la cultura, el espacio social extra doméstico donde transitan y gobiernan los hombres. Consideraciones similares forman parte del pensamiento de los ilustrados mencionados aquí y de otros igualmente considerados clásicos del pensamiento europeo, con contadas excepciones. 
Reproducir, es decir domesticar fenómenos naturales, simples o complejos, a voluntad humana es la prueba que la humanidad, parte misma de la naturaleza, consiguió someterla, pero no pudo prescindir de la parte de aquella que lo invade: su propio cuerpo; condición material de posibilidad de su existencia racional. Por tanto, Descartes reduce el devenir del cuerpo a ser una máquina, lo subalterniza explicándolo como un mero un mecanismo bajo el control de la mente o "alma" en sentido aristotélico,

(...) la muerte nunca ocurre por culpa del alma, sino porque algunas de las principales partes del cuerpo se corrompe. Juzguemos que el cuerpo de un hombre vivo difiere de aquel de un hombre muerto como un reloj o cualquier otra cosa automática (esto es otra máquina que se mueve por si mesma) (...) y mismo el reloj o cualquier otra máquina cuando estuviera quebrada y cuando el principio de su movimiento deja de funcionar. (Descartes, [1649] 2017, p. 37)

Si el cuerpo es un mecanismo, una máquina o una "fábrica" retomando las ideas de Andrés Vesalio (1555), entonces el saber para repararlo cuando se desgasta o funciona mal es un saber técnico, racional, con potencialidad de saber científico. La medicina que estuvo mucho tiempo sumergida en la desvalorización de las prácticas cotidianas, fue elevada desde Descartes en adelante al carácter de ciencia. A partir de allí una división de las tareas de mantenimiento de la salud del cuerpo se binariza entre médicos y mujeres. Desde la identificación de la enfermedad, que varía cultural e históricamente según tipificaciones, la solución es territorio médico. Los médicos ahora científicos contarían con el arsenal cognitivo necesario. En cambio, el mantenimiento cotidiano de la salud del cuerpo, la provisión de los insumos para su funcionamiento normal, las tareas preventivas para garantizar su durabilidad y aptitud en el tiempo son responsabilidades de operarias domésticas sin retribución ni valorización social, porque tales tareas formarían parte de su instintividad - por ejemplo, el "instinto maternal" - y dotaciones "naturales" de su femineidad. Después de todo, caballos, bueyes, perros etc. nunca cobraron tampoco por su trabajo, ni demandaron reconocimientos por ello.

Todo aquello que ocurre en el mundo natural - lo que incluye al cuerpo y no se puede someter o controlar por la racionalidad científica ni a la domesticidad, queda en la jurisdicción temporaria de lo mágico-religioso y del poder estatal. La influencia de este pensamiento es tal en diversos espacios de la cultura occidental, que por ejemplo la Historia tradicional ${ }^{3}$ se centró en el

\footnotetext{
${ }^{3}$ Sin desconocer otros aportes pioneros como los de Le Goff y Truong (2005), Duby y Perrot (1993), en su muy prolífica y vasta obra sobre historia de las mujeres en Occidente, y en otros títulos, así como otros exponentes de la escuela historiográfica francesa en sus diferentes etapas. El cuerpo humano también tiene una presencia "temprana" en la Antropología, aunque como manifestación y materialización de la cultura, en los debates "cultura-naturaleza" fundamentados por los clásicos del campo como Lévi-Strauss (1962) y Marcel Mauss ([1936]1979) entre otros.
} 
tiempo y en la auto referencialidad de la experiencia humana, como si estuviese desprovista de un cuerpo. El ethos humano, el sujeto de la historia, construido desde lo cultural, subordinando e invisibilizando su animalidad. Al respecto Harari (2018) apunta que

Durante mucho tiempo, el Homo Sapiens prefirió concebirse a si mismo como separado de los animales (...) gustemos o no somos miembros de una familia grande e particularmente ruidosa chamada grandes primates. Nuestros parientes vivos más próximos incluyen los chimpancés, los gorilas y los orangutanes (p.18)

La secularización de la sociedad a consecuencia del impacto de la Ilustración en Occidente a partir del siglo XVIII, implicó un ascenso de la Medicina como "saber oficial" sobre el cuerpo (Le Breton, 2002) de la mano de los incipientes estados nacionales en los actos regulatorios del "buen" funcionamiento de los cuerpos (Turner, 2014) en tanto materialidad de la población, materia prima de la ciudadanía de los estados nacionales.

La Medicina profesionalizada y como brazo regulador de la gobernanza del Estado sobre los cuerpos de sus ciudadanos, desplazó tempranamente a las mujeres sacando de la esfera doméstica los principales momentos de la vida humana, que se expresan principalmente a través de la corporalidad-nacimiento, reproducción, enfermedad y muerte- para llevarlos al hospital, (Foucault, [1963] 2015) es decir bajo la tutela estatal. Turner coincide con Foucault en cuanto a que,

El Estado regula el cuerpo por medio de la interferencia de una variedad de aparatos ideológicos, especialmente por medio del Derecho de Familia y de la medicina preventiva. (...) En ese sentido las normas religiosas de una buena vida fueron transferidas la medicina; el resultado es que ésta como ciencia supuestamente neutra, ultrapasa los limites tanto del derecho como de la religión al proveer criterios de normalidad. (2014, p. 283)

Estados nacionales, ciencias y religiones monoteístas universalizadas de origen mediterráneo, coinciden desde hace siglos en un aspecto central para esta reflexión: la necesidad de control y sometimiento de la expresión de la animalidad que está radicada en el cuerpo humano. Así, la triada "enfermedad, pecado y crimen"4 en palabras de Turner (2014), en la línea de pensamiento de esta comunicación aparecería como resultante directo o indirecto, del incumplimiento por parte de las mujeres de un contrato social firmado sin ellas:

\footnotetext{
${ }^{4}$ Podemos colocar como ejemplo al tratamiento dado desde la expansión de las religiones monoteístas a la homosexualidad, cuestión que se prolonga hasta nuestros días. Recién en 1990, la Organización Mundial de la Salud y la comunidad médica en general, dejó de tratar a la homosexualidad como enfermedad. En algunos países, la triada "enfermedad, pecado y delito" conjugados en la homosexualidad, todavía goza de total vigencia.
} 
responsabilizarse, sin reclamar por ello compensación material o simbólica, de la higiene corporal, doméstica, moral y psicológica, de la alimentación corporal y espiritual, de la adecuación a la sociabilidad de un lugar y tiempo social concretos; es decir cuidando de los aspectos cotidianos, monótonos y alienantes de la vida humana, disimulándolos detrás de los muros del hogar para que esa vulnerabilidad intrínseca no se proyecte al espacio público lugar de la competencia, la innovación, el arte y las ideas "elevadas".

La discursividad, religiosa, jurídica, normativa y hasta médica sigue considerando el trabajo de cuidados, en gran medida hasta el presente, obligaciones "naturales" de las mujeres, tal que, si no lo realizan adecuadamente, son culpadas por innúmeras problemáticas de la convivencia social ${ }^{5}$. Por cuidado de las personas se entiende aquí, a un conjunto de prestaciones que pueden ser individuales, grupales y colectivas, domésticas o institucionalizadas en la forma de bienes y servicios que insumen de tiempos, energías y especializaciones que es capaz de brindar supervivencia vital, soporte afectivo, estabilidad psicológica, integración y adaptación social y hasta nutrición espiritual (Ferro, 2020) aunque bajo la tutela del Higienismo, es decir de las recomendaciones médicas.

El Higienismo, movimiento político de sanidad pública consecuencia de la alianza entre los incipientes estados nacionales y la Medicina desde finales del siglo XVIII comienza a mirar con detenimiento a la vida doméstica como parte de las condiciones de vida colectivas de los sectores populares. Como nos informa Czeresnia (1997),

Ciertas condiciones de vida, con todo, dicen respecto a naciones enteras o a la mayor parte de la población, y en cuanto los individuos en sus vidas particulares siempre son portadores y la expresión de situaciones y condiciones, normales y anormales, todavía así, las manifestaciones de la vida, cuando modificadas por condiciones espaciales y temporales pueden aparecer de una manera tan masiva que podemos permitirnos hablar de salud y enfermedad del pueblo de una manera abstracta, mismo que no sea lo ideal. (Virchow citado en Czeresnia,1997, p. 57)

Mientras la medicina pública al servicio del Estado y de los particulares, en cuanto mayoritariamente ejercida por hombres durante mucho tiempo, es

\footnotetext{
${ }^{5}$ Cuando surgen las organizaciones obreras en el siglo XIX y debaten socialmente las condiciones laborales, rápidamente se estigmatiza el trabajo femenino extra doméstico "El trabajo industrial femenino comenzó a provocar indignación pública, disfrazada la mayor parte de las veces de preocupaciones morales. También la prensa obrera condenaba al trabajo extra doméstico, considerándolo perjudicial para la salud y la prole. Anarquistas y socialistas apuntaban sus consecuencias nocivas: tuberculosis, prostitución y abandono de los niños. El trabajo fabril era visto como un desperdicio físico de energías femeninas y como factor de la disolución de la salud y de la capacidad de desempeño de las funciones maternales. Comprometía además la dignidad de la mujer, a la que se consideraba culpable de la mortalidad infantil y responsable de los desórdenes sociales." (Samara \& Matos, 1993, p. 780).
} 
remunerada y reconocida socialmente tanto como trabajo y como saber científico; en cambio quienes mantienen los cuerpos sanos y con vida en forma cotidiana con su tiempo, energías y especialización (Ferro, 2020) lo hacen a título honorario en cuanto mujeres, dotadas "naturalmente" para ello.

En el presente, las ideas iniciadas por el Higienismo y continuadas por la Epidemiología, siguen tutelando moral y epistemológica del trabajo de cuidados. Tales mensajes, lejos de desenfocarse apenas en las mujeres para así democratizarlos socialmente, se hicieron omnipresentes y más generizados todavía, mediante sinergia con los intereses mercantiles de las industrias químicas y farmacológicas desde el siglo pasado cuanto menos y sin solución de continuidad en el presente. Para comprobar esto basta ver los contenidos factuales y simbólicos de la publicidad de productos, tanto los que constituyen insumos para el trabajo doméstico como aquellos para el trabajo reproductivo. Por ejemplo, la limpieza de la "cueva", casa/habitación de los núcleos de convivencia, que expresa la publicidad de productos de limpieza del hogar y de insumos para la crianza, casi siempre dirigida hacia las mujeres en forma directa, idealiza una fisonomía laboratorial para connotar eficiencia. Una batalla química, parte de una guerra sin cuartel contra gérmenes y bacterias que forman parte del séquito indeseable, aunque convenientemente invisible del cuerpo humano, como el de cualquier otro cuerpo animal o vegetal. Cuando las operarias/combatientes domésticas pierden alguna/s de esas diarias batallas por intentar desempeñarse en el espacio público al igual que los hombres, se presentaría la enfermedad en el ámbito familiar.

En la actualidad, el lenguaje del Higienismo con foco doméstico, adopta cada vez más claramente un lenguaje marcial otorgando carácter épico a las abnegadas combatientes domésticas en la batalla contra las bacterias y otros organismos invisibles en el hogar, que acechan amenazando la salud de los integrantes de los núcleos familiares en una analogía muy clara con el lenguaje de enfrentamiento al enemigo invisible de la pandemia por COVID-19 en estos días.

También en el marco de ideas individualistas que predominan en nuestras sociedades pos-modernas, el cuerpo es asumido como localización material de la soberanía del "yo", sin lugar para pensar en sus intrínsecas dependencias. En palabras de Le Breton, "En nuestras sociedades occidentales, entonces, el cuerpo es el signo del individuo, el lugar de su diferencia, de su distinción. Paradójicamente, al mismo tiempo, está disociado de él a causa de la herencia dualista..." (2002, p. 9).

\section{Descolonizando antecedentes}


A pesar que en esta actual crisis sanitaria global, los medios de comunicación en general reflejan como antecedentes de esta pandemia por COVID 19, apenas a la Gripe española de principios del siglo XX, el antecedente estructural más directo y significativo en términos de magnitud, fue aquella ocurrida en territorio hoy llamado americano en la conquista y colonización española desde finales del siglo XV. Es oportuno considerar diferencias entre conceptos muy utilizados, sin precisión conceptual, por estos días. En ese sentido Moura y Rocha (2012) proponen que,

Endemia puede ser conceptuada como la ocurrencia de un agravante dentro de un número esperado de casos para aquella región, en aquel período de tiempo, basado en su ocurrencia en años anteriores no epidémicos. De esta forma, la incidencia de una enfermedad endémica es relativamente constante, pudiendo ocurrir variaciones estacionales en el comportamiento esperado para el agravamiento en cuestión. Epidemia representa la ocurrencia de un agravamiento encima de la media (o mediana) histórica de su ocurrencia. El agravamiento causador de una epidemia tiene generalmente aparición súbita y se propaga por determinado período de tiempo en determinada área geográfica, afectando frecuentemente a un elevado número de personas. Cuando una epidemia impacta varios países de diferentes continentes, pasa a ser denominada pandemia (p.15).

Esa pandemia en el mundo conocido de entonces, tuvo desplazamiento intercontinental debido los cuerpos en movimiento a través de las vías de comunicación existentes, tal como ocurre actualmente, siendo parte de un proceso más amplio a escala global que Le Roy Ladurie (1973) calificó como "la unificación microbiana del mundo". Esta unificación microbiana del mundo habría ocurrido entre los siglos XIV al XVII como consecuencia de la expansión del imperialismo europeo, entre otros varios procesos expansivos simultáneos, aunque de menor escala protagonizado por otros grupos en el mundo.

En territorio americano, las epidemias jugaron un rol central en la consolidación de la invasión europea como comprobaron Jared Diamond (2013) y Alfred Crosby (2011) entre otros historiadores ambientales ${ }^{6}$, debido particularmente a la significación política dada a la asimetría de la letalidad de la misma en los grupos étnicos confrontados: a quienes mataba y a quienes dejaba vivir. Integrantes de pueblos originarios colonizados morían por centenas de

\footnotetext{
${ }^{6}$ Y antes también: la teoría más fuerte de la despoblación del imperio maya siglos antes de la llegada de los españoles es la de una epidemia traída por invasores, también originarios, que habrían llegado desde el oeste en el Katun 4 ahau, diezmando a la población maya ocasionando el abandono de sus ciudades y refugiándose los sobrevivientes en las zonas rurales. (Guerra citado em Borah, 2000, p.20; François XavierGuerra [1942-2002] fue un importante historiador hispano-francés, quien realizó contribuciones tempranas acerca del protagonismo que tuvieron las epidemias en la Conquista americana por parte de los europeos).
} 
miles en poco tiempo, mientras los invasores europeos parecían casi inmunes. Como plantean Lovell y Cook (2000),

Una tras otra las enfermedades procedentes del Viejo Mundo asolaron el continente americano, siguiendo rutas bien establecidas de comercio y comunicación. El impacto de la enfermedad era diferente según varios factores, pero para el siglo diecisiete la población aborigen se había reducido significativamente, con una consiguiente alteración irreversible de la vida y las costumbres autóctonas (p. 9).

Varios siglos después, se sabría que la asimetría en la letalidad del impacto epidemiológico en dicha etapa, podría tener que ver con el efecto inmunológico llamado de "suelo fértil" o "virgen", debido a la barrera sanitaria que los Océanos Atlántico y Pacífico habrían interpuesto por milenios desde la separación de los continentes ${ }^{7}$ a los diferentes grupos humanos instalados en sus márgenes. En palabras de Borah (2000),

se trata de que una enfermedad introducida en poblaciones que nunca antes la han experimentados o que han estado libres de ella por tanto tiempo, que cualquier inmunidad adquirida ha desaparecido, atacará masivamente a tales poblaciones sin respetar sexo ni edad. En consecuencia, la mortalidad es sumamente alta e incluso total (p. 21).

La dramática despoblación indígena, como resultado de las epidemias causadas por agentes patógenos que llegaron a estos territorios, integrando según Crosby (2011) "biotas portátiles", definida como "una designación colectiva para los europeos y todos los organismos que ellos cargaron consigo" (p. 280) provenientes de otros ecosistemas del escenario atlántico, no solo habrían llegado provenientes de Europa sino también de África Subsahariana debido a las millares de personas esclavizadas de origen africano que trajeron y emplazaron desde el Norte al Sur de las Américas, así como aquellas integradas por plantas y animales originarios de ecosistemas de dominios asiáticos y oceánicos, cultivados y criados en estos territorios desde la conquista.

Por todo ello, Diamond (2013) propone a los gérmenes, inesperada arma de guerra de conquista - "la mayoría de los españoles no comprendía las razones del fenómeno" (Lovell \& Cook, 2000, p.250) - como coprotagonistas de la misma junto al uso de los metales en armamentos. Pronto la asimetría del

\footnotetext{
${ }^{7}$ Esa barrera sanitaria habría podido ser atravesada en algunas oportunidades ocasionales y sin continuidad según proponen varias teorías de contactos entre los territorios hoy llamados americanos y pueblos noreuropeos y africanos, bastante antes de la llegada de los españoles a finales del siglo XV, como postula, entre otros, el arqueólogo brasilero Walter Neves (v. Neves y Piló, 2008). Aunque como todo al respecto del poblamiento americano está siempre en controversia. Hasta el momento la más aceptada es la teoría del ingreso de humanos desde Asia a través del Estrecho de Bering hace por lo menos 12.000 años antes de nuestra era. También migraciones posteriores desde la Polinesia se encuentran bien documentadas formando parte del modelo de las tres migraciones en la formación de la población americana.
} 
impacto de las epidemias fue muy aprovechada por los invasores en sus alcances político-religiosos, como señalan estos autores. La explicación más usual creída o no, por muchos de los colonizadores, especialmente los religiosos, tenía que ver con que era una forma de castigo divino hacia los pueblos originarios por su paganismo y renuencia a ser evangelizados en muchos casos ${ }^{8}$. En esa línea argumentativa, la inmunidad de los europeos tendría que ver, con su temprana aceptación de la fe cristiana. (Phelan citado en Lovell \& Cook, 2000, p. 250; John Leddy Phelan [1924-1976] fue un importante historiador americano quien dedicó gran parte de su obra intelectual a realizar aportes de la historia colonial latino-americana y de las Filipinas).

Como entonces, como siempre, la emergencia sanitaria global puede relajarse sin embargo lo que permanece son los significantes fortalecidos o inventados en el periodo pandémico. Castigo de los dioses en la era pagana, "Juicios secretos de Dios" en la era cristiana, moralización sexual en la pandemia del Síndrome de Inmunodeficiencia Adquirida (SIDA), en las últimas décadas del siglo XX. Esta nueva experiencia ya presencia la disputa de sentidos para significarla: parte de la crisis ambiental para algunos, a quien Hipócrates quizás les daría bastante razón, corolario de una supuesta crisis del capitalismo tardío para otros, entre varios sentidos que se disputan un lugar semiológico. En la línea argumental de este trabajo, el epicentro de la infección viral de Wuhan (China) en el mercado de animales salvajes, donde esos animales son tratados en las formas más bárbaras, el coronavirus habría saltado de huéspedes no humanos a humanos. Eso demuestra una crueldad en el trato a la vida y muerte no humana - no exclusiva de esa región sino que muy extendida en el globo - relacionada a una idea de jerarquía y de diferencia, antropocentrismo, que tiene que ser cimentada por la violencia dada sus borrosas y endebles bases.

Finalmente, por más interconectados que estemos a escala global a través de nuestras cada vez más rápidas e integradas vías de comunicación, seguimos siendo "suelo fértil". El coronavirus nos alerta que el contador inmunológico parece volver siempre a cero, como nos enseña la crisis sanitaria global en nuestro presente.

\section{La civitas como lugar y forma de ocultación de la animalidad humana}

\footnotetext{
${ }^{8}$ La idea de la enfermedad como castigo por la falta de armonía del individuo doliente con su y en el plano espiritual fue largamente utilizada en situaciones individuales desde los inicios mismos de las religiones monoteístas. También, para las religiones llamadas animistas y panteístas propias de los pueblos originarios americanos hasta la actualidad, la enfermedad corporal es la consecuencia de una falta de afinidad en el mundo espiritual "Era asociada a algo que entra en el cuerpo, como espíritus, posesiones demoníacas o flechas lanzadas por los dioses." (Czeresnia, 1997, p.48) y por ello la cura comienza en ese plano y se evidencia luego en el cuerpo.
} 
La experiencia de la pandemia está intrínsecamente ligada a la experiencia urbana de nuestra especie. Desde que se inició la urbanización hace por lo menos 6.000 años antes de nuestra era (Harari, 2018) no dejamos de profundizar el proceso hasta nuestros días, con aceleraciones y amesetamientos en distintos periodos, pero siempre creciendo. La polis aparece como el lugar donde la animalidad humana residente en el cuerpo se domestica y se la llama civilidad.

La urbanización fue condición de posibilidad de la multiplicación poblacional y ésta a su vez fue posibilitada por la previsibilidad de la comida, la mayor parte del tiempo, resultado de la Revolución Agrícola y esencialmente por la efectividad del resguardo, así como la disponibilidad de cuidados. Pero por estar tan urbanizados somos también más vulnerables a las pandemias, convivir juntos y amontonados nos expone más a la transmisión de enfermedades, porque son nuestros cuerpos los que se aproximan finalmente y somos a partir de ellos "biotas portátiles" donde quiera que estemos o nos traslademos.

En el pensamiento contemporáneo, frecuentemente, la idea de naturaleza además de ser construida binariamente por fuera de lo humano, también es concebida como vida biológica residente fuera de la ciudad. La ciudad como conjunto, más o menos organizado, de guaridas de materiales inorgánicos, más o menos resistentes, resguarda la vulnerabilidad corporal humana. Pero la vida biológica dentro de la ciudad, existe y es tan o más intensa, que aquella más alejada de las guaridas de concreto.

Toda clase de especies animales y vegetales están dentro y fuera de las guaridas que los primates humanos construyen con cuatro objetivos principales: 1) proteger del clima la vulnerabilidad de sus cuerpos, 2) protegerse de otros depredadores, incluyendo humanos 3 ) ocultar funciones naturales propias de los mamíferos higienizando sus excrecencias y residuos 4) resguardar la cría en el periodo más crítico de su fragilidad, que dura bastantes años.

Esta vulnerabilidad corporal se simula tras la ropa, en tanto primates sin pelos $^{9}$ (Jablonsky, 2006) y tras los muros, así como la realización cotidiana de las funciones fisiológicas comunes con todos los mamíferos como defecar, dormir, copular, comer y otros imperativos pertenecientes al ámbito de la "irracionalidad biológica". Vivir en las ciudades implica una cercanía entre cuerpos que trasladan a donde van no solo sus necesidades sino también sus secreciones, olores, virus, bacterias y gérmenes. La higiene corporal nos permite mantener una ficción precaria de no animalidad que apenas dura unas cuantas horas, dependiendo de circunstancias climáticas y fisiológicas.

\footnotetext{
${ }^{9}$ Del mismo modo que la pérdida progresiva de los pelos en la superficie de la piel de los homínidos, cuyo caso extremo es el Homo Sapiens, incrementó su vulnerabilidad corporal al mismo tiempo que potenció sus habilidades comunicativas, ya que sin pelos en la cara las expresiones faciales que manifiestan emociones fueron más fácilmente visibles para otros miembros de la especie y de otras especies de mamíferos que se relacionan con los humanos.
} 
El baño, como sitio doméstico y como práctica, concentra un arsenal químico cada vez más numeroso y sofisticado con el cual combatimos olores, secreciones, y hasta arrancamos la poca vellosidad restante, para intentar colocar frente a otro/os un cuerpo aséptico. Pero la higiene corporal, condición mínima para esa convivencia apiñada en ciudades que nos caracteriza, es una batalla que se pierde todos los días, como una alegoría cósmica, con cadencia astronómica. Desde líderes/esas religiosos/as, científicos/as premiados/as con el Nobel, top models, excelsos/as intérpretes y compositores/as de música, hasta sencillos/as agricultores/as, analfabetos/as etc. después de un día o dos del más concienzudo baño y de la aplicación de una plétora de fragancias químicas, olemos todos/as como bichos.

Las ciudades también nos proveen de una miríada de recursos para el sostenimiento y la extensión de nuestro tiempo individual de vida, pero a la vez subrayan la progresiva profundización de nuestra vulnerabilidad en muchos aspectos. Por ejemplo, éstas nos permiten estar cada vez menos tiempo a la intemperie, estamos encerrados la mayor parte del tiempo diario en nuestras guaridas y salimos de ellas para entrar en cajas metálicas que se mueven. El cielo sobre nuestras cabezas va teniendo, generación tras generación, cada vez menos espacio en nuestras experiencias sensoriales.

\section{El cuerpo como ambiente}

El cuidado del ambiente concebido como aquello por fuera de lo humano, utilizado por éste para satisfacer sus necesidades, tiene un reconocimiento social y político que todavía le es negado al cuidado del cuerpo y sus circunstancias. Aun desde la perspectiva ecologista el cuerpo humano es excluido como ambiente. Se instala socialmente la necesidad de transformación de la relación entre la especie humana y la naturaleza entendiendo ésta como una dimensión fuera de lo humano y de la ciudad.

Desde la dimensión ética, se propone el cuidado del ambiente como una racionalidad o espiritualidad humana desprovista de carnalidad propia. Sin embargo, el cuerpo humano es un ambiente en sí mismo, conformando junto con otros cuerpos - orgánicos y no orgánicos - el ambiente en sentido amplio. Primer territorio habitado, es decir espacialidad humana primera y última, el cuerpo es una porción, un recorte del ambiente en sentido amplio. Humanos y no humanos nos impactamos mutuamente e interaccionamos porque formamos parte de estructuras de la vida más amplias y que nos abarcan.

Actualmente es reconocible el impacto causado por la ambientalización de las Ciencias Sociales y Humanidades en las Teologías cristianas, evidenciándose esto en la aparición de la Teología Ambiental, fuertemente impulsada en el ámbito católico desde la aparición de la Encíclica Papal de 
Francisco (2015) Laudato Si. El cuidado de la casa común. Podría interpretarse que el pensamiento de San Francisco de Asís es recuperado, desde el mismo nombre papal, para superar el antropocentrismo cristiano con raíces en las culturas clásicas y así intentar mejorar la relación de lo humano con la Creación, sinónimo teológico para "naturaleza".

Este posicionamiento en la llamada comúnmente "Encíclica Verde o Ecológica”, por la inédita reivindicación ambiental que expresa, abre la puerta para ir más lejos. En el propio Cántico de las criaturas cuerpos orgánicos e inorgánicos de la creación son colocados en igual sacralidad que lo humano, por provenir de la misma voluntad creadora: "Alabado seas, mi Señor, por nuestra hermana muerte corporal" (Francisco de Asís [1226] citado en Naranjo Boza, 2006, p. 39). Así, la sacralidad de lo humano no sería antitética con la resignificación y revalorización de nuestra animalidad, desde que se extienda la idea de sacralidad de todo lo creado en el Oikos: la casa común. La teología de Francisco de Asís es un cuestionamiento de la idea antropocéntrica que, aun proviniendo del pensamiento clásico greco-romano y por ello pagano, se incrustó fuertemente en el pensamiento cristiano: lo humano creado a imagen del Dios creador está jerárquicamente por encima de todo lo creado y que puede servirse de todo lo que está puesto en la tierra de la manera que sus necesidades y deseos le indiquen.

Sin extender la idea de conciencia a los organismos inanimados que emparentaria esta propuesta al animismo, la equipotencia de la sacralidad del zoe - en sentido aristotélico - es decir, de la vida que compartimos con el resto de los organismos se mantendría a distancia también, del antropocentrismo largamente gravitante en nuestra cultura moderna y contemporánea que la pandemia actual contribuye a cuestionar.

¿Por qué es más fácil asumir teológica, moral y políticamente el cuidado del ambiente que el trabajo de cuidados doméstico? ¿Por qué el trabajo de cuidados, su valoración social y su necesaria redistribución a escala interpersonal y sistémica social no consigue ser una bandera política, una ética cristiana?

\section{El cuidado como denuncia de la persistente animalidad humana}

El impacto más significativo de las pandemias en el mundo occidental es que insisten en colocar en evidencia algo persistentemente negado, invisibilizado o subalternizado: la animalidad humana que radica en la existencia, vicisitudes y vulnerabilidad inmanente del cuerpo. En nuestros días, todo un aparato de mensajes y advertencias nos piden encerrar nuestros cuerpos en los hogares y si inevitablemente tenemos que permanecer en espacios públicos, mantenerlos apartados entre sí a una distancia segura. Cada cuerpo es 
involuntariamente transformado en arma biológica de una "guerra invisible", sin importar objeciones intelectuales, morales y religiosas de su portador una vez que, eventualmente, una carga viral de mayor o menor magnitud lo haga su huésped. Los sistemas inmunológicos que portamos no parecen dar cuenta de la situación, ni tampoco lo habrían podido hacer en las crisis predecesoras: "nunca antes habíamos visto una pandemia que pudiera ser controlada" (Organización Mundial de la Salud, 2020).

La vulnerabilidad corporal coloca límites intrasponibles a la idea de superación constante de todo obstáculo "natural" mediante el progreso técnico. Ni siquiera la sofisticación alcanzada por la medicina responsable en gran parte, pero no excluyente, de la extensión de la vida y del progresivo envejecimiento de las poblaciones actuales se muestra capaz de conculcar una vulnerabilidad constituyente, una animalidad inconvenientemente expuesta. Como subraya Harari (2018),

Los humanos nacen prematuramente, cuando muchos de sus sistemas vitales todavia están subdesenvolvidos. Um potro pode trotar logo após o nascimento; um gatinho deixa a mãe para buscar alimento por conta própria com poucas semanas de vida. Os bebês humanos são indefensos e durante muchos anos dependem dos mais velhos para o seu sustento, proteção e educação. (p. 24)

La esfera pública moderna postuló consignas abstractas en relación al inevitable e irrefrenable progreso humano en todas las áreas de su actividad, depositando gran parte de tales expectativas en la ciencia: "Las teorías de acción social disponibles son típicamente caracterizadas por lo que se podría llamar un sesgo cognitivo que ignora la corporalidad humana en la realidad carnal del agente social" (Turner, 2008, p.9). En tanto, movimientos de mujeres y feministas al colocar en la agenda pública las complejidades del sostenimiento cotidiano de la materialidad de la vida humana pretenden colocar la "carne" humana y sus circunstancias en el centro de la política y del pensamiento social. Una razón más para incomodar al patriarcado racional-tecnocrático que trata a las mujeres como trata a la naturaleza, en el entender de Shiva y Mies (1997).

Esta carnalización de la movilización política por parte de las mujeres no solo tiene que ver con las agendas reivindicativas relativas a la sexualidad desde mediados del siglo $X X$, sino que han estado presentes desde antaño en los reclamos organizados de las mujeres por los precios de la comida, por las constantes matanzas de jóvenes en las guerras decididas por los señores de la tierra y del poder político (Thébaud, 1993), entre una vasta agenda de demandas por la conservación de la vida humana.

Desde mediados del siglo XX, a conquista parcial de aspectos de la soberanía del propio cuerpo, como el control químico de la fertilidad femenina, por parte de movimientos de mujeres y feministas mediante movilizaciones, 
represiones y batallas argumentativas en el espacio público, colocó el cuerpo en la agenda pública y especialmente en los ámbitos académicos ${ }^{10}$ con una fuerza inédita: "El cuerpo es la mas potente metáfora de la sociedad" (Turner, 2014,p.161). La anticoncepción química fue condición de posibilidad de entrada de masas críticas de mujeres, de camadas medias, a la educación superior y en consecuencia incrementaron expresivamente su participación en los mercados laborales. Según Yasmine Ergas (citado en Soihet, 2015; Ergas es una investigadora y profesora italiana especialista en movimientos feministas en la contemporaneidad occidental).

Una fuerte característica de los feminismos de la Europa Occidental y Estados Unidos, entre las décadas de 1960 y 1980 fueron las "políticas del cuerpo" (...) buscando las mujeres la plena asunción de su cuerpo y de la sexualidad (aborto, placer y anticoncepción) e rebelándose contra la violencia sexual. (p. 281).

La carnalización de la política y del debate social que propician los movimientos de mujeres y feministas en la contemporaneidad reconoce dos dimensiones. Por una parte la soberanía sobre el propio cuerpo en aspectos que van desde la reproducción a la sexualidad y por otro, el cuestionamiento sobre la histórica atribución exclusiva del cuidado de la vida en todos sus aspectos de los demás integrantes del grupo familiar, incluso de adultos sanos, generalmente hombres con los que mantienen relaciones afectivas, capaces de tener autonomía en el cuidado de sí y que además no dividen con las mujeres el cuidado de los dependientes familiares, así como la responsabilidad estatal y del sector privado en el mismo:

Los datos relevantes de los estudios sobre el uso del tiempo nos indican que es reduccionista pensar que las únicas personas que utilizan el trabajo doméstico y de cuidado son los niños y niñas y los ancianos y ancianas. Detrás de las personas débiles se esconden también personas fuertes, sobre todo varones adultos, que utilizan el trabajo doméstico y de cuidado de las mujeres como apoyo fundamental para la sostenibilidad de su vida, no sólo en periodos de crisis, sino también, y sobre todo, en la normalidad cotidiana. (Picchio, 2001, p. 3)

La vulnerabilidad humana, comienza a dejar de ser escondida en los hogares y se rechaza la tercerización de su gestión a título honorario sobre las mujeres. Se intenta dar dimensión política, económica, espiritual y moral a la

10 A excepción de la Filosofía para la cual el problema cuerpo-alma existe desde los inicios de su delimitación como campo de conocimiento. 
cuestión del cuidado en medio de una estructural crisis global de provisión de los mismos (Ferro, 2020) que se entrelaza con la crisis sanitaria en desarrollo.

\section{Conclusiones}

El impacto de una pandemia va más allá de su letalidad biológica, es decir de los cuerpos que enferma y/o mata. Los sentidos y significantes que las sociedades afectadas construyen sobre esa experiencia es lo que explica la perdurabilidad de las transformaciones políticas sociales, económicas y culturales que promueve. Las narrativas que los grupos humanos utilizan para racionalizar, comprender y asimilar la experiencia de la pandemia pueden ser intencionadas o espontáneas por parte de sus protagonistas, pero en todo caso excede un análisis puramente biológico, médico o epidemiológico strictu sensu.

Todo lo que vive, depende. Es decir, el bios del planeta tiene la potencia de la vida y el movimiento que ella permite, pero al precio de la vulnerabilidad de la dependencia respecto de otros organismos y hasta de lo inanimado. Un caso elocuente de esto último es la gradual e irreversible incorporación de la dimensión ciborg en nuestra existencia corporal. El ápice de la concepción del cuerpo como máquina en tanto algunos órganos de materiales no carnales comienzan a ser implantados en el cuerpo posibilitándole sobrevida cuando sus originales órganos fallan o se desvían en su funcionamiento normal, daría cuenta de cuerpos híbridos: "Un ciborg es un organismo cibernético, un híbrido de máquina y organismo, una criatura de realidad social y también de ficción" (Haraway, 1991, p. 253). Los ciborgs también se contagian.

Para estar vivo no alcanza con nacer y portar un cuerpo sano y perfectamente funcional según los requerimientos de cada sistema social. Para seguir vivo, desde el momento de nacer hasta la autonomía funcional y en muchos casos hasta que llega el momento de la muerte natural, es imperativo ser cuidado. Nuestras sociedades tienden a reconocer el valor del cuidado que se encuentra inmerso en las instituciones sanitarias y es llevado a cabo por diversas especialidades de los servicios públicos y privados de salud a los que llegan los cuerpos enfermos o en periodos críticos de su devenir vital, pero tiene dificultades en visibilizar y reconocer que eso es apenas la punta del iceberg porque esos cuerpos son mantenidos vivos y sanos la mayor parte del tiempo gracias a los cuidados recibidos en los hogares recayendo en nuestros días todavía casi en exclusividad - sobre los tiempos y energías de las mujeres. A pesar de los profundos cambios experimentados en la etapa contemporánea en la mayor parte de las sociedades respecto a la participación de las mujeres en los espacios públicos, la histórica y desigual distribución del trabajo de cuidados entre hombres y mujeres persiste. 
Y esta dependencia del cuidado, no solo en la enfermedad sino sobre todo en la salud considerando este concepto en su multidimensionalidad, es proyección de nuestra persistente animalidad en simultáneo con la sofisticación tecnológica y relacional que posibilita nuestra cultura, es decir nuestro modo de ser y estar en el mundo concreto e ideal que nos contorna. En más de 200.000 años de existencia de Homo Sapiens conseguimos llegar a Marte, caminar por la Luna, comunicarnos en tiempo real con otra persona en cualquier punto del globo terráqueo, sin embargo, no conseguimos eliminar una sola de las funciones fisiológicas propias de mamíferos. Aun si se está en la Estación Espacial Internacional reparando partes de sofisticadas ingenierías astronómicas hay que comer, ir al baño, dormir etc. en simultáneo. La ficción civilizatoria se sostiene por la ocultación de todo aquello que hace del cuerpo un dispositivo animal, mediado por la repetitiva y continua actividad posibilitadora de la neutralización de tales circunstancias corporales: el trabajo de cuidados, tanto remunerado como no remunerado.

El futuro pos-biológico no existe como posibilidad para nuestra especie por tanto para convivir con la siempre presente vulnerabilidad corporal debería tornarse al cuidado una consigna civilizatoria, una ética transhumana no sexuada y más allá del sanitarismo. Para ello precisa ser resignificado y desgenerizado, quizás esta pandemia nos deje esta lección.

\section{Referencias}

Borah, W. (2000). Introducción. In: G. Lovell \& N. Cook (Ed.) Juicios secretos de Dios. Epidemias y despoblación indígenas en hispano-américa colonial (pp. 1730). Trad.: Jorge Gómez. Quito: Editorial Abya Yala.

Crosby, A. (2011). Imperialismo ecológico. A expansão biológica da Europa 9001900. Trad.: José Augusto Ribeiro, Carlos Afonso Malferrari. São Paulo: Companhia das Letras.

Czeresnia, D. (1997). Do contágio à transmissão. Ciência e cultura na gênese do conhecimento epidemiológico. Rio de Janeiro: FIOCRUZ.

Descartes, R. ([1649] 2017). As paixões da alma. Trad.: Ciro Mioranza. São Paulo: Lafonte Editores.

Diamond, J. (2013). Armas, germes e aço. Os destinos das sociedades humanas. Trad.: Sílvia Costa. Rio de Janeiro: Edições Record. 
Duby, G. \& Perrot, M. (Dir.). Historia de las Mujeres en Occidente. Tomo V, Siglo $X X$. Trad: Marco Galmarini. Madrid: Taurus.

Ferro, S. L. (2020). Care`s global crises, transnational migrations and remittances. Impacts in and from Latin America. Cidades, comunidades e territórios 40: 88-102.

Foucault, M. ([1963] 2015). O nascimento da clínica. Trad.: Roberto Machado. São Paulo: Forense Universitária.

Harari, N.Y. (2018). Sapiens. Uma breve história da humanidade. Trad.: Janaína Marcantonio. Porto Alegre: L\&PM Editores.

Haraway, D. (1991). Ciencia, cyborgs y mujeres. La reinvención de la naturaleza. Trad.: Manuel Talens. Madrid: Cátedra.

Hobbes, T. ([1651] 1980). Leviatán. Trad.: Antonio Escohotado. Madrid: Editora Nacional.

Jablonsky, N. G. (2006). Front Matter. In: N. Jablonsky, Skin: A Natural History (pp. 1-6). Los Angeles-London: University of California Press.

Ladurie, E. (1973). Un concept: I'unification microbienne du monde (XIVe - XVIIe siècles). Berne: Société Générale Suisse d'Histoire.

Le Breton, D. (2002). Antropologia del cuerpo y la Modernidad. Trad.: Paula Maher. Buenos Aires: Ediciones Nueva Visión.

Le Goff, J. \& Truong, N. (2005). Una historia del cuerpo en la Edad Media. Trad.: Josep Pinto. Barcelona: Editorial Paidós.

Lévi-Strauss, C. (1962). Le penseé sauvage. Paris: Librairie Plon.

Lovell, G. \& Cook, N. (2000). Desenredando la madeja de la enfermedad. In: G. Lovell \& N. Cook (Ed.). Juicios secretos de Dios. Epidemias y despoblación indígenas en hispanoamérica colonial (pp. 17-30). Trad.: Jorge Gómez. Quito: Editorial Abya Yala.

Mauss, M. ([1936]1979). Sexta parte: Las técnicas del cuerpo. In: M. Mauss. Sociología y Antropología (pp.309-336). Madrid: Tecnos. 
Moura, A. S. \& Rocha, R.L. (2012). Endemias e Epidemias: dengue, leishmaniose, febre amarela, influenza, febre maculosa e leptospirose. Belo Horizonte: NESCON-UFMG. Retirado de https://www.nescon.medicina.ufmg.br/biblioteca/imagem/3285.pdf

Naranjo Boza, N. (2006). Deformación y cambios en esencia al "Cántico de las criaturas" de san Francisco de Asís en la versión de Ezra Pound. Íkala, revista de lenguaje y cultura 17: 33-72.

Neves, W. A. \& Piló, L. B. (2008). O povo de Luzia: em busca dos primeiros americanos. São Paulo: Globo.

Organización Mundial de la Salud (2020). Alocución de apertura del Director General de la OMS en la rueda de prensa sobre la COVID-19 celebrada el 11 de marzo de 2020 Retirado de https://www.who.int/es/dg/speeches/detail/whodirector-general-s-opening-remarks-at-the-media-briefing-on-covid-19---11march-2020

Papa Francisco (2015). Laudato Si. De la casa común. Ciudad del Vaticano. Retirado de https://www.vatican.va/content/francesco/es/encyclicals/documents/papafrancesco_20150524_enciclica-laudato-si.html

Picchio, A. (2001). Un enfoque macroeconómico "ampliado" de las condiciones de vida. Conferencia inaugural del Taller Internacional Cuentas Nacionales de Salud $y$ Género. Retirado de https://www.fundacionhenrydunant.org/images/stories/biblioteca/GeneroMujer-Desarrollo/enfoque\%20macroeconomico\%20ampliado.pdf

Roldán, C. (2013). Ni virtuosas ni ciudadanas. Inconsistencias prácticas en la teoría de Kant. Ideas y valores 62: 185-203.

Rousseau, J. J. ([1755] 1999). Discurso sobre el origen de la desigualdad entre los hombres. Alicante: Biblioteca Virtual Miguel de Cervantes. Retirado de http://www.cervantesvirtual.com/obra-visor/discurso-sobre-el-origen-de-ladesigualdad-entre-los-hombres--

Samara, E. M. \& Matos, M. S. (1993). Manos femeninas, trabajo y resistencia de las mujeres brasileñas (1890-1920). In: G. Duby \& M. Perrot. (Dir.). Historia de las Mujeres en Occidente. Tomo V, Siglo XX (pp.775-786). Trad: Marco Galmarini. Madrid: Taurus. 
Shiva, V. \& Mies, M. (1997). Ecofeminismo. Teoría, crítica y perspectivas. Trad.: Mireia Boffil. Barcelona: Icaria-Antrazyt.

Soihet, R. (2015). Feminismos, sexualidade e anticoncepção nos anos 1960-1980 In: T. Parente. \& C. Miranda (Org.). Arquiteturas de gênero. Questões e debates (pp. 281-314). Palmas: EDUFT.

Thébaud, F. (1993). El impuesto de la sangre. In: G. Duby \& M. Perrot (Dir.) Historia de las Mujeres en Occidente. Tomo V. Siglo XX (pp.79-84). Trad: Marco Galmarini. Madrid: Taurus.

Turner, B. S. (2014). Corpo e Sociedade. Estudos em Teoria Social. Trad.: Maria Mourão. São Paulo: Ideias e Letras Edições.

Vesalio, A. ([1555] 2005) Facsímil. De humani corporis fábrica, libris septem. Madrid: Sankyo Pharma España. 